given to our patient to influence the course of his infection with a highly sensitive organism. Although no penicillin was found in the pus aspirated before he received intrapleural injections, the high serum level $(8 \mathrm{mg} / \mathrm{l})$ together with the presence of a substantial amount of metronidazole in this specimen, and of doxycycline in subsequent ones, and his prompt response to treatment with this drug, make it highly improbable that the failure of parenteral penicillin could have been due to its failure to reach the site of the infection.

The evidence suggests that the inactivating agent was an enzyme arising from the cell walls of the leucocytes. At first sight its pattern of inactivation of $\beta$-lactam antibiotics suggest that it was not a $\beta$-lactamase, but the effect of $\mathrm{pH}$ on its activity against penicillin and ampicillin raises the question of whether other $\beta$-lactam antibiotics are similarly affected.

Since we began this work, specimens of pus received from two other patients have been tested for their ability to inactivate penicillin. Neither had this property, but de Louvois and Hurley, ${ }^{1}$ who have recently been examining specimens of pus with this object, report that four out of 22 were able to inactivate penicillin to a variable degree. Thus the phenomenon may be relatively common, though it may only be of clinical significance where there is a collection of pus, as in an empyema or a joint, and seemingly it will be accentuated where the pus is of low $\mathrm{pH}$. It may account, however, for some unexplained failures of penicillin treatment. Nevertheless, the failure of our patient to respond to the high concentration of penicillin that must have been achieved by the intrapleural injection of $600 \mathrm{mg}$ - which resulted in an adequate concentration still being present three days later-remains unexplained.

We thank Dr Lyall Watson for his permission to report on a patient under his care, and Dr D Gardner for his helpful advice on the properties of enzymes.

\section{Reference}

${ }^{1}$ De Louvois, J, and Hurley, R, British Medical fournal, 1977, 1, 998.

(Accepted 17 February 1977)

\title{
High TSH concentrations in "euthyroidism": explanation based on control-loop theory
}

\section{Summary}

High concentrations of thyroid-stimulating hormone (TSH) in the serum have often been reported in apparently euthyroid patients with damaged thyroids. We have confirmed this finding in 14 patients 18 months after subtotal thyroidectomy for Graves's disease (group 1) and in 14 patients with manic-depressive psychosis (group 2) receiving lithium carbonate, which reduces thyroid reserve. One factor common to groups 1 and 2 but not to the controls was reduced thyroid reserve or functioning capacity, and, using established physical principles of servo-control, we have tried to define the mechanism. A series of curves were projected to indicate how TSH might be expected to vary with functioning thyroid capacity.

\section{Introduction}

Raised thyroid-stimulating hormone (TSH) concentrations have been reported in apparently euthyroid patients with symptomless thyroiditis ${ }^{12}$ after radioiodine treatment for thyrotoxicosis, ${ }^{3}{ }^{4}$ and subtotal thyroidectomy. ${ }^{5}{ }^{6}$ Evered et al claimed that a raised serum TSH concentration is the most sensitive index of

\footnotetext{
Ninewells Hospital and Medical School, and Carnegie Laboratory of Physics, University of Dundee

T J WILKIN, MB, MRCP, lecturer in therapeutics

B E STOREY, BSC, PHD, senior lecturer in physics

T E ISLES, BSC, PHD, senior lecturer in biochemical medicine

J CROOKS, MD, FRCP, professor of therapeutics

J SWANSON BECK, MD, FRCPATH, professor of pathology
}

thyroid failure and placed patients with normal circulating thyroid hormone but raised TSH concentrations into a group designated "subclinical hypothyroidism." Himsworth and Fraser ${ }^{8}$ found this terminology confusing and argued that to divide euthyroid patients into two arbitrary groups according to their serum TSH concentrations may conceal other determinants of TSH secretion. Functioning thyroid mass or capacity (FTC) has been tentatively suggested as one such determinant, ${ }^{3+8}{ }^{9}$ but to date no attempt has been made to evaluate its importance. (FTC is defined in terms of the thyroid response to a standard concentration of TSH.)

\section{Present series}

Study $A$ was carried out on three groups of 14 subjects with nearidentical (within $1 \mathrm{nmol}(0.8 \mathrm{\mu g}) / \mathrm{l})$ free thyroxine (FT4) indices. Group 1 comprised 14 women who were clinically (Billiewicz's diagnostic index ${ }^{10}$ ) and biochemically (FT4 index and serum triiodothyronine (T3) concentration) euthyroid 18 months after subtotal thyroidectomy for Graves's disease; group 2,12 women and two men, all biochemically (FT4 index and serum T3) euthyroid and all under treatment for manic-depressive psychosis with enough lithium carbonate to obtain therapeutic plasma levels of 0.8-1.1 mmol (5.6-7.6 $\mathrm{mg}$ )/ (lithium at these concentrations reduces the thyroid response to $\mathrm{TSH}^{11}$ ); and group 3,14 healthy women cleaners all biochemically (FT4 index and serum T3) euthyroid, who acted as controls (see table). No subject in group 1 or 3 was receiving any form of medication. There was no significant difference in mean serum $\mathrm{T} 3$ concentrations between the groups.

Study $B$ was carried out on a 56-year-old woman with severe hypothyroidism due to Hashimoto's thyroiditis during incremental replacement with thyroxine. TSH and the FT4 index were measured before treatment and again at monthly intervals before each increment $(25 \mu \mathrm{g})$ in the dose of thyroxine.

Serum $\mathrm{TSH},{ }^{12} \mathrm{~T} 4,{ }^{13}$ and $\mathrm{T} 3^{13}$ were measured by radioimmunoassay. T3 uptake was measured by a method similar to Thyopac-3 (Radiochemical Centre, Amersham), and the FT4 index derived from the ratio of $\mathrm{T} 4: \mathrm{T} 3$ uptake expressed as a percentage. 


\section{Results}

Study $A$-There was no significant difference in mean FT4 indices or serum T3 concentrations between the groups (table). The mean TSH concentrations in groups 1 and 2 , however, were significantly higher than in group $3(\mathbf{P}<0.05$ and $\mathbf{P}<0.01$ respectively; fig 1$)$. Wilcoxon's signed ranking test ${ }^{14}$ was used for serum TSH owing to its non-parametric distribution and the presence of undetectable levels in groups 1 and 3. For the same reasons it was not possible to derive absolute values for mean TSH.

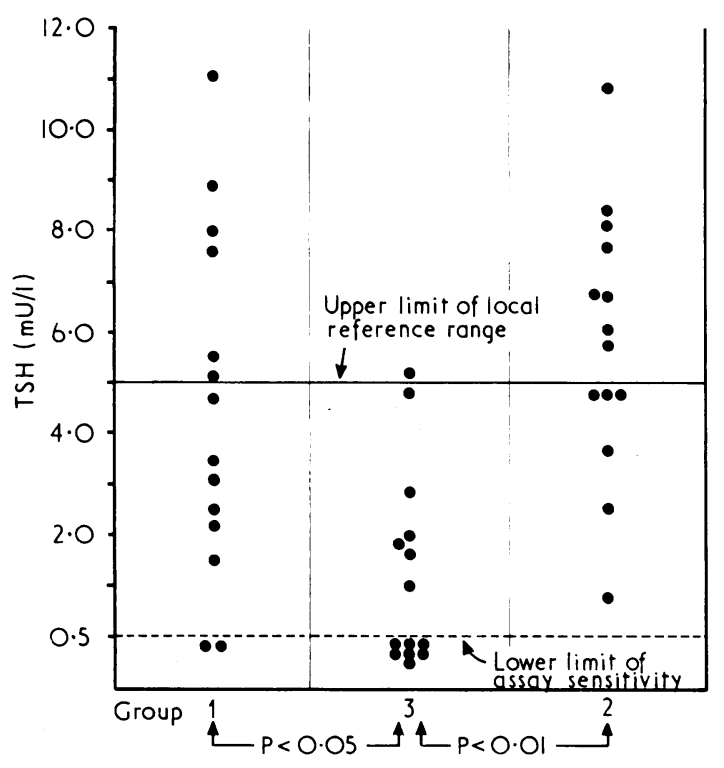

FIG 1-Individual TSH concentrations in the three groups studied. Mean concentrations in groups 1 and 2 were significantly higher than in group 3 .

Study B-The curve defining the fall in TSH with incremental doses of thyroxine is shown in fig 4. It was linear when expressed semilogarithmically.

\section{Discussion}

The pituitary control of the thyroid incorporates a feedback loop, so that plasma TSH tends to increase as thyroid hormone (TH) concentration falls and vice versa. ${ }^{15}$ Our results from patients and controls matched for $\mathrm{TH}$ concentration, however, suggest that another factor, acting independently of $\mathrm{TH}$, may also influence TSH. Furthermore, our findings, supported by those of others, ${ }^{1-6}{ }^{9}$ suggest that the characteristics conventionally attributed to the thyroid-pituitary feedback loop ${ }^{1516}$ are not sufficient to account for all its observed behaviour. The feature common to patients who have had thyroidectomy ${ }^{17}$ and to those receiving lithium ${ }^{11}$ (and to patients treated with radioiodine $^{18}$ or suffering from asymptomatic thyroiditis $\left.{ }^{17}\right)$ is diminished FTC. We have therefore referred back to the principles of control-loop theory in search of a factor that would link FTC with TSH independently of TH.

\section{CONTROL-LOOP THEORY}

Fig 2 shows a simple proportional control loop designed to ensure that response (signal 3) corresponds faithfully with command (signal 1) irrespective of perturbing influences. ${ }^{19}$ The two principal components of the loop are the comparator $(\mathrm{C})$, which senses any difference between response and command, and the servo-generator (S-G), which corrects that difference according to a control signal from the comparator. Such a control loop has three fundamental characteristics. ${ }^{19}$

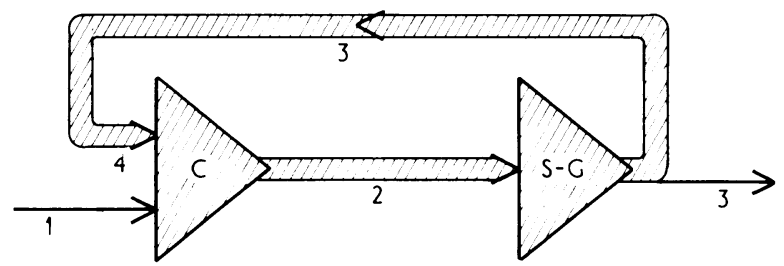

FIG 2-Simple proportional control loop (hatched lines). Design ensures that response (signal 3) corresponds to command (signal 1). Failure results in error signal (4), which is sensed by comparator $(\mathrm{C})$. Comparator amplifies error signal and produces control signal (2), which drives servo-generator $(S-G)$ in direction and to degree appropriate to minimising error. Size of residual error is function of loop gain.

Error signal-The error signal is the difference (or error) between command and response signals. The comparator constantly monitors the relation between command and response signals and amplifies any error (signal 4) by a factor known as comparator gain. The control signal (signal 2) is therefore determined solely by the error signal and their ratio by the magnitude of the gain. If the command signal remains constant, changes in the control signal will be determined solely by movement in the response signal (fig 2).

Loop gain-The comparator is only one stage in the loop at which the signal is amplified. The servo-generator is another, and the product of their gains defines the "loop gain" of the system-that is, the factor by which the error signal is amplified in completing one circuit of the loop. Loop gain is a fundamental concept: its magnitude is crucial to the operation of a control system because it determines the size of error signal tolerated by the system. Accordingly a system with low loop gain may exist in stable equilibrium with a sizeable error signal, while a high-loop-gain circuit will seek to correct even the smallest error.

Saturability-Saturation is defined as the point at which the response of a component fails to rise with further increase in input. Both comparator and servo-generator are saturable. A control loop in which either component is saturated has zero loop gain: it no longer controls and can be said to have failed. Saturation may be achieved by exceeding a critical input (overload) either by a primary increase in the signal or by so reducing the efficiency of the component that to obtain the desired output inevitably leads to overload (fig 3). Depending on the design and demands of the system, saturation of the servo-motor could be reached at very high loop gain and correspondingly small error signal. (We have chosen to represent a saturation characteristic

Age, sex, and circulating thyroid hormone concentrations in the three groups studied

\begin{tabular}{|c|c|c|c|c|c|c|c|c|}
\hline \multirow{2}{*}{ Group } & \multicolumn{2}{|c|}{ No of subjects } & \multirow{2}{*}{$\underset{\text { (years) }}{\text { Mean age }}: S D$} & \multirow{2}{*}{$\mathbf{P}$} & \multirow{2}{*}{$\begin{array}{c}\text { Mean FT4 index : SD } \\
(\text { nmol:1) } \\
(\text { normal 70-140) }\end{array}$} & \multirow{2}{*}{$\mathbf{P}$} & \multirow{2}{*}{$\begin{array}{c}\text { Mean T3 } ; \text { SD } \\
(\text { nmol } \mathrm{I}) \\
(\text { normal } 0 \cdot 8-2 \cdot 5)\end{array}$} & \multirow{2}{*}{$\mathbf{P}$} \\
\hline & $\mathrm{F}$ & $\mathrm{M}$ & & & & & & \\
\hline 1 (post-thyroidectomy) & 14 & & $35 \div 10$ & $<0.01$ & $105 \cdot 4: 14 \cdot 0$ & \} NS & $1.92+0.22$ & \} \\
\hline 3 (controls) & 14 & & $47 \div 11$ & & $105 \cdot 7: 14 \cdot 0$ & & $1.85: 0.35$ & 3 \\
\hline 2 (lithium-treated) & 12 & 2 & $54-14$ & NS & $105 \cdot 4+14 \cdot 0$ & \}$\quad$ NS & $1.77 \pm 0.35$ & \} \\
\hline
\end{tabular}

NS = Not significant

Conversion: SI to traditional units-FT4 index: $1 \mathrm{nmol} / 1 \approx 0.8 \mu \mathrm{g} / \mathrm{l}$. T3: $1 \mathrm{nmol} / 1 \approx 0.65 \mathrm{ng} / \mathrm{ml}$. 


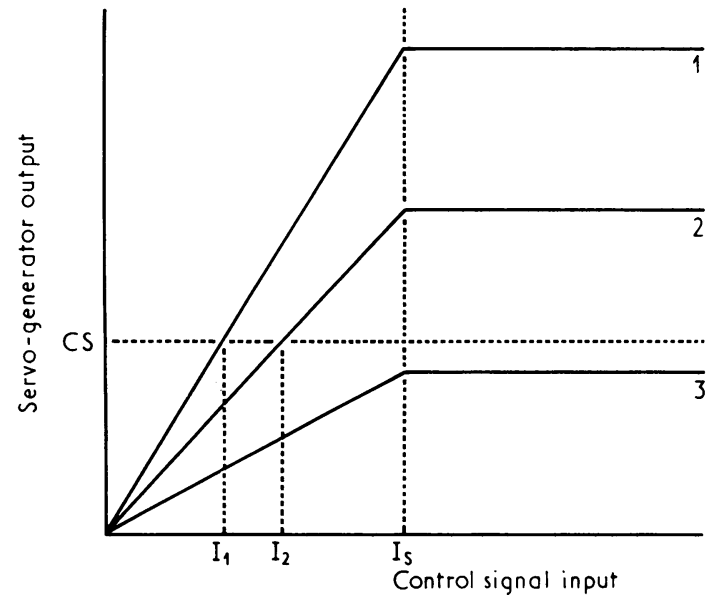

FIG 3-Performance of servo-generator designed to saturate independently of gain operating at three different efficiencies $(1,2$, and 3$)$. CS indicates level of output needed to comply with command signal. At efficiencies 1 and 2 motor will operate adequately to produce appropriate output, although higher control signal $\left(I_{2}\right)$ is necessarily required at efficiency 2 than at efficiency $1\left(I_{1}\right)$. At efficiency $3\left(I_{S}\right)$, however, generator enters saturation before achieving desired output. (Linear model shown.)

that is independent of gain: a gain-dependent characteristic would be equally viable and would not alter the influence of loop gain on the quality of control.)

\section{PHYSIOLOGICAL CONTROL OF TH}

In applying these principles to the physiological loop controlling $\mathrm{TH}$ concentrations, which appears to be of similar design, ${ }^{16}$ we are ascribing to the pituitary the role of comparator and to the thyroid the role of servo-generator. Accordingly, we are suggesting that (with stable pituitary function) TSH concentration is determined solely by the difference between thyrotrophin-releasing hormone $(\mathrm{TRH})$ and $\mathrm{TH}$ concentrations

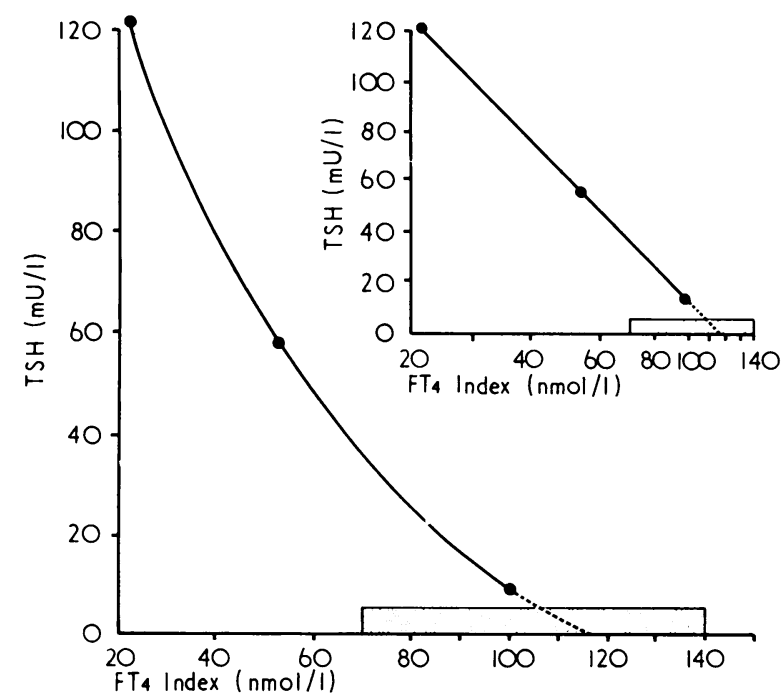

FIG 4-Curve relating TSH and FT4 index to changes in FTC in patient with spontaneous hypothyroidism undergoing replacement therapy with monthly increments of thyroxine. Curve has been extrapolated to intercept $\mathrm{x}$ axis at FT4 index value that represents maximum attainable for patient's TRH if loop gain were infinite (zero TSH indicates zero error signal). Stippled area encloses local reference ranges for TSH and FT4 index. (Inset: same data expressed semilogarithmically.)

Conversion: SI to traditional units-FT4 index: $1 \mathrm{nmol} / 1 \approx 0.8$ $\mu \mathrm{g} / 1$. and that loss of FTC (from any cause) reduces loop gain. When the thyroid enters saturation (failure) the loop loses control of $\mathrm{TH}$ concentration and any subsequent change in TH becomes a simple function of FTC. The error signal would be expected to widen rapidly after saturation, being reflected by an acceleration in the rise of TSH.

The TSH response to rising serum T4, obtained from a patient with Hashimoto's thyroiditis during replacement therapy with thyroxine, is shown in fig 4 . The relation appears to be linear when expressed semilogarithmically and has been extrapolated on that basis. Probably the curve expresses equally well the original changes in TSH and FT4 index as loop gain diminished with her thyroiditis - that is, a growing divergence of FT4 index from some point near the maximum attainable for her particular concentration of TRH (about $115 \mathrm{nmol} / 1 ; 92$ $\mu \mathrm{g} / \mathrm{l})$. Had there been no fall in loop gain with progression of her thyroiditis the curve would have been expected to lie vertically.

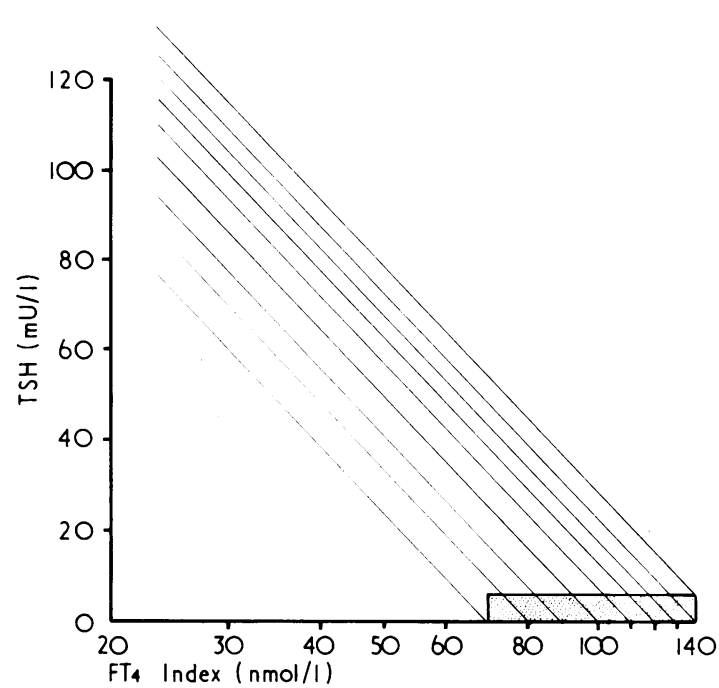

FIG 5-Family of constant TRH curves drawn semilogarithmically (see fig 4) to illustrate in principle how FT4 index and TSH might change with thyroid efficiency in nine subjects with different TRH concentrations spanning reference range for FT4 index. (Gradients indicate pituitary gain and are subject to individual variation.) Stippled area encloses local reference ranges for TSH and FT4 index.

Conversion: SI to traditional units-FT4 index: $1 \mathrm{nmol} / 1 \approx$ $0 \cdot 8 \mu \mathrm{g} / 1$.

The curve suggests, however, that a deviation from optimum of only 5-10 units in the FT4 index was enough to raise her serum TSH above the upper limit of normal $(5.0 \mathrm{mU} / \mathrm{l})$. Such a movement in FT4 index is unlikely to produce symptomatic hypothyroidism and is barely significant in terms of assay precision. To this extent the opposing views of Evered et $^{\mathrm{al}}{ }^{7}$ and Himsworth and Fraser, ${ }^{\circ}$ over use of the term subclinical hypothyroidism may be reconciled. The slightest fall in loop gain is inevitably accompanied by a downward deviation in FT4 index, though if it is the product of a high-gain circuit the change in $\mathrm{TH}$ need be neither clinically obvious nor even biochemically measurable.

Reichlin et $a^{16}$ produced a similar curve relating TSH to serum protein-bound iodine in thyroidectomised rats and hypothyroid patients undergoing $\mathrm{T} 4$ replacement and showed that the curve could be displaced to the left by reducing TRH. If the function of the pituitary-thyroid loop is to maintain a close correspondence between $\mathrm{TH}$ and TRH then TRH probably has a distribution in a healthy population similar to that of TH. Accordingly we envisage a family of constant TRH curves (shown in principle in fig 5) based on control-loop theory ${ }^{19}$ and supported by the observation illustrated in fig 4 . 
Each curve defines the variation of TSH and TH with thyroid efficiency at a particular TRH concentration, with limits that correspond to the normal range of FT4 index $(70-140 \mathrm{nmol} / \mathrm{l}$; $54.5-109.0 \mu \mathrm{g} / \mathrm{l})$. The disposition of such curves is highly reminiscent of the dose-response curves obtained with a drug in the presence of varying doses of antagonist, ${ }^{20}$ consistent with the concept that the physiological error signal measured as serum $\mathrm{TSH}$ is the net result of a competitive antagonism between thyroid hormone and TRH at pituitary level. ${ }^{21}$ The existence of such curves would provide a plausible explanation for high TSH concentrations in otherwise euthyroid people whose FTC was reduced through any cause. Furthermore, they question the validity of a rise in TSH concentration above the reference range as a strict criterion of hypothyroidism unless it is contended that very minor deviations from optimum serum T4 require replacement therapy. Thyroid failure might then be logically defined as the point at which thyroid function becomes saturated. This is the point beyond which the fall in TH would be expected to accelerate and is analogous to the definition of organ failure applied to other body control systems-for example, cardiac and respiratory.

In any event the TSH concentration, being a directly measurable function of the error signal, appears to be the most sensitive index of thyroid state currently available, and loop gain the factor that links the two.

We acknowledge the co-operation of Drs A M M Shepherd and $\mathrm{J} \mathrm{J}$ Manns in providing access to their data on a hypothyroid patient receiving T4-replacement therapy, and thank Drs D S Hewick and G J Naylor for data on lithium-treated patients, Drs P S Brown (department of pharmacology, Bristol University) and $\mathbf{R}$ Brown (department of mathematics, Dundee University), for advice, and Mrs Joyce Simpson and Dr Elizabeth Hunter for laboratory help.
This work was supported by a Scottish Hospital Endowments Research Trust grant to JSB.

Requests for reprints should be addressed to: $\mathrm{Dr} \mathrm{T} J$ Wilkin, Department of Therapeutics, Ninewells Hospital, Dundee DD2 $1 \mathrm{UB}$.

\section{References}

1 Gordin, A, et al, Acta Endocrinologica, 1974, 75, 274.

2 Vanhaelst, L, and Bastenie, P A, Nouvelle Presse Médicale, 1975, 4, 1813.

3 Toft, A D, et al, Lancet, 1973, 2, 644.

4 Tunbridge, W M G, Harsoulis, P, and Goulden, A W G, British Medical fournal, 1974, 2, 89.

${ }^{5}$ Hedley, A J, et al, Lancet, 1971, 1, 155.

${ }^{6}$ Evered, D, et al, British Medical fournal, 1975, 1, 25.

7 Evered, D, et al, British Medical fournal, 1973, 1, 657.

${ }^{8}$ Himsworth, R L, and Fraser, P M, British Medical fournal, 1973, 2, 295.

๑ Henneman, G, et al, British Medical fournal, 1975, 4, 129.

10 Billiewicz, W Z, et al, Quarterly fournal of Medicine, 1969, 38, 255.

11 Villeneuve, A, et al, International fournal of Clinical Pharmacology, 1974, 1,75 .

12 Hall, R, Amos, J, and Ormston, B J, British Medical fournal, 1971, 1, 582.

${ }^{13}$ Seth, J, Toft, A D, and Irvine, W J, Clinica Chimica Acta, 1976, 68, 291.

14 Wilcoxon, F, Biometrics Bulletin, 1945, 1, 80.

15 Hoskins, R G, fournal of Clinical Endocrinology, 1949, 9, 1429.

16 Reichlin, S, et al, Recent Progress in Hormone Research, 1972, 28, 229.

17 Jeffries, W McK, et al, fournal of Clinical Endocrinology, 1956, 16, 1438.

18 Slingerland, D W, fournal of Clinical Endocrinology, 1972, 35, 912.

19 Dransfield, P, Engineering Systems and Automatic Control. Englewood Cliffs, NJ, Prentice-Hall, 1968.

20 Goldstein, A, Aronow, L, and Kalman, S M, Principles of Drug Action, 2nd edn, p 89. New York, Wiley, 1974.

21 Vale, W, Burgus, R, and Guillemin, R, Proceedings of the Society of Experimental Biology and Medicine, 1967, 125, 210.

(Accepted 15 February 1977)

\title{
Plasma immunoreactive corticotrophin and lipotrophin in Cushing's syndrome and Addison's disease
}

\author{
J J H GILKES, LESLEY H REES, G M BESSER
}

British Medical fournal, 1977, 1, 996-998

\section{Summary}

Plasma immunoreactive corticotrophin (ACTH) and lipotrophin (LPH) were measured in patients with raised circulating concentrations from a pituitary or an ectopic source. They were measured again in seven patients after they had received hydrocortisone. Plasma ACTH concentrations were higher than LPH concentrations in patients with a pituitary source of their homones, whereas this relation was reversed when the source was ectopic. After hydrocortisone administration the half

\footnotetext{
Department of Dermatology, University College Hospital and University College Hospital Medical School, London WC1

J J H GILKES, MD, MRCP, consultant dermatologist

St Bartholomew's Hospital, London EC1

LESLEY H REES, MD, MRCP, senior lecturer, department of chemical pathology

G M BESSER, MD, FRCP, professor of endocrinology
}

\begin{abstract}
life of immunoreactive ACTH was 40 minutes and that of LPH 95 minutes, resulting in a reversal of the normal relation of ACTH to LPH. The use of two antisera with different specificities for measuring LPH has further shown that pituitary LPH differs from ectopic LPH. Relatively less $\gamma$-LPH than $\beta$-LPH was produced from ectopic sources, the relation being reversed in patients with a pituitary source for their raised concentrations.

Measuring plasma LPH as well as ACTH might therefore help in deciding whether a patient with Cushing's syndrome has a pituitary or ectopic source of ACTH, which sometimes presents a difficult clinical problem.
\end{abstract}

\section{Introduction}

Abe et $a l^{1}$ showed a close relation between plasma immunoreactive corticotrophin $(\mathrm{ACTH})$ and $\beta$-melanocyte-stimulating hormone $(\beta-\mathrm{MSH})$ concentrations in patients with increased secretion from a pituitary or ectopic source. Since then, however, the molecule of small molecular weight that has been identified as human $\beta-\mathrm{MSH}$ has been shown to be a breakdown product derived during in-vitro extraction from larger molecules$\beta$ - and $\gamma$-lipotrophin $(\mathrm{LPH}) .{ }^{2}$ There is no evidence that $\beta$-MSH 